\title{
Control of Cortical Neuron Migration and Layering: Cell and Non Cell-Autonomous Effects of p35
}

\author{
Vicki Hammond, ${ }^{1}$ Li-Huei Tsai, ${ }^{2}$ and Seong-Seng Tan ${ }^{1}$ \\ ${ }^{1}$ Howard Florey Institute, The University of Melbourne, Victoria 3010, Australia, and 2Department of Pathology and Howard Hughes Medical Institute, \\ Harvard Medical School, Boston, Massachusetts 02115
}

The migration, arrest, and ultimately positioning of cortical neurons require signaling activity from Reelin as well as from cyclindependent kinase $5(\mathrm{Cdk} 5)$. Although both molecules control neuronal positioning, they achieve their effects by quite separate molecular pathways. Cdk5 is a serine-threonine kinase, the activity of which is dependent on its activating subunits p 35 and p39. Mice deficient in Cdk5, p35, or both p35 and p39 display the hallmarks of disturbed cortical development, including cortical layer inversion, neuronal disorientation, and abnormal fiber infiltration. To distinguish between the cell- and non cell-autonomous functions of p35, we constructed $p 35^{+/+} \leftrightarrow p 35^{-/-}$chimeras using the lacZ gene as an independent marker for $p 35^{+/+}$cells. In this shared developmental space, wild-type and mutant neurons behaved cell-autonomously with respect to layering. Wild-type cells formed a properly layered supercortex that is mirrored by an inverted mutant cortex lying underneath. However, this genotype-specific behavior was confined to the pyramidal population, and interneurons belonging to either genotype were indiscriminately distributed. However, there was also non cell-autonomous rescue of mutant neurons, and this rescue was specific only to early-born pyramidal neurons belonging to layer $\mathrm{V}$. Rescued neurons reached the correct layer address and possessed appropriate neuronal morphology, orientation, and projections. Later-born neurons belonging to layers II and III were not rescued. These results demonstrate that p35 signaling can have both cell- and non cell-autonomous consequences, and their effects are not uniformly shared by cortical neurons born at different times or born at different places (projection neurons vs interneurons).

Key words: p35; Cdk5; development; cortex; migration; layering; GABA

\section{Introduction}

During cortical development, at least two signaling pathways are thought to be involved in the control of neuronal positioning that is responsible for cortical lamination. One of these is the Reelinsignaling pathway, whereas the other involves cyclin-dependent kinase 5 (Cdk5) and its activators p35 and p39 (for reviews, see Dhavan and Tsai, 2001; Rice and Curran, 2001; Gupta et al., 2002). Mice deficient in genes of the Reelin-signaling pathway, which includes reelin, disabled-1 (Dab1), very low-density lipoprotein receptor, and apolipoprotein E receptor 2, exhibit abnormal neuron migration during development leading to cortical layer inversion and other patterning disturbances in the hippocampus and cerebellum (D’Arcangelo et al., 1995; Howell et al., 1997; Sheldon et al., 1997; Trommsdorff et al., 1999). In contrast, $C d k 5^{-1-}, p 35^{-1-}$, or $p 35^{-1-} / p 39^{-1-}$ compound mutants have quite separate cortical lamination problems and less severe hippocampal and cerebellar distortions, in keeping with the defective operation of a separate biochemical pathway (Ohshima et al.,

Received July 8, 2003; revised Nov. 14, 2003; accepted Nov. 21, 2003.

This work was supported by a program grant from the National Health Medical Research Council and a Kenneth Myer Foundation grant. We thank Brian Howell for the gift of Dab1 mutant mice, Yi-Ping Hsueh for the Tbr-1 antibody, Frank Weissenborn for expert technical assistance, and Fiona Christensen for making the chimeras.

Correspondence should be addressed to Seong-Seng Tan, Brain Development Laboratory, Howard Florey Institute, The University of Melbourne, Parkville 3010, Victoria, Australia. E-mail: stan@hfi.unimelb.edu.au.

D01:10.1523/JNEUROSCI.4529-03.2004

Copyright $\odot 2004$ Society for Neuroscience $\quad$ 0270-6474/04/240576-12\$15.00/0
1996; Chae et al., 1997; Gilmore et al., 1998; Kwon and Tsai, 1998; Ko et al., 2001). Nonetheless, recent studies indicate that these pathways may function synergistically with biochemical crosscommunication between Cdk5 and Dab1 (Ohshima et al., 2001; Keshvara et al., 2002). In the neocortex, $C d k 5^{-1-}$ and $p 35^{-1-}$ mice exhibit normal neuronal migration up to the point of layer VI formation, after which subsequent waves of migrating neurons appear incapable of venturing past earlier-born neurons (Ohshima et al., 1996; Chae et al., 1997; Gilmore et al., 1998). The net result is inversion of upper cortical layers (II-V) that are set quite apart from a properly developed, although malpositioned, layer VI (Gilmore et al., 1998; Kwon and Tsai, 1998).

The precise function of Cdk5/p35 during cortical development is unclear; however, because p35 is not expressed in proliferating neuronal progenitors (Tsai et al., 1994; Zheng et al., 1998), this signaling pathway is believed to be concerned chiefly with the migration and positioning of neurons after they cease to divide (Delalle et al., 1997). Thus, despite widespread expression of Cdk5 in the nervous system (Tsai et al., 1993; Ino et al., 1994; Zheng et al., 1998), the spatial and temporal limits of p35 expression would appear to quarantine p35-initiated kinase activity to postmitotic cortical neurons. At the cellular level, p35 is detected in neuronal cell bodies and processes and in the growing tips of axons and neurites including callosal fiber tracts (Nikolic et al., 1996; Tomizawa et al., 1996). In mice without a functional $p 35$ gene, the neocortex exhibits three hallmarks of disrupted devel- 
opment (Chae et al., 1997). First, there is inversion of the six cortical layers, although, unlike the reeler mutant, the migration of the earliest generated neurons appears to be unaffected. Second, pyramidal neurons possess abnormal dendritic morphology and orientation with their apical dendrites bereft of their typical radial alignment. The result is malpositioning of disoriented neurons throughout the cortical wall. Third, aberrant fiber tracts are seen to course inappropriately through the lower and middle cortical layers, resulting in reduced thickness of the corpus callosum and altered axonal trajectories.

However, it is unclear whether the above phenotypes have arisen from cell-autonomous or non cell-autonomous mechanisms of p35 dysfunction, or even a combination of both activities. A moot point is whether or not $p 35$ mutation is directly responsible for all observable phenotypes in the cortex. For instance, to what extent can some of these abnormalities be attributed to secondary (or non cell-autonomous) effects of cortical layer inversion and its associated cytoarchitecture disruption? According to this argument, the observed neuronal disorientation may be secondary to a disorganized cortical environment following lamina reversal. Similarly, fiber infiltration into the neocortex associated with callosal axon defasciculation may represent a non cell-autonomous response to p35-induced changes to neuronal orientation rather than from intrinsic p35 signaling defects at the axonal growth cone tips. These distinctions are important for defining the different facets of $p 35$ gene function and for understanding the role of the $\mathrm{Cdk} 5 / \mathrm{p} 35$ genetic pathway during cortical development.

Chimeras offer a powerful way of distinguishing between intrinsic and extrinsic effects of gene function during cortical development (Gilmore and Herrup, 2001; Hammond et al., 2001). In this study, we created chimeras wherein the developing neocortical space is inhabited by a mixture of $p 35^{-/-}$and $p 35^{+/+}$ neurons. We used an independent lac $Z$ marker for distinguishing wild-type cells to investigate the effects of $p 35^{+/+}$cells on neighboring $p 35^{-1-}$ mutant cells with respect to neuronal migration, layering, and dendritic orientation. Although the presence of wild-type neurons was not able to rescue the layer inversion of mutant cells, and mutant cells did not disrupt layering of wildtype neurons, certain aspects of the mutant phenotype were rescued, such as the positioning and dendritic orientation of earlybut not late-born pyramidal neurons. In addition, partitioning of the cortical space was dependent on $p 35$ genotype and mediated by pyramidal neurons. In contrast, interneurons from both genotypes appear capable of migrating into cortical areas consisting of either mutant or wild-type cells. We conclude that cortical neurons generated at different times and from different parts of the germinal zones may respond differently to p35 signaling activity, and such responses may translate into either cell- or non cell-autonomous effects.

\section{Materials and Methods}

Chimeras. To generate $p 35^{+/+} \leftrightarrow \mathrm{p} 35^{-/-}$chimeras ( $p 35^{-/-}$chimeras), we fused 8-cell stage morulas from $\mathrm{H} 253$ mice carrying the lac $Z$ reporter gene together with $p 35^{-1-}$ morulas (Mintz, 1970). The latter were produced from intercrossing heterozygous $p 35^{+/-}$mice (maintained on C57BL/6J $\times$ DBA background). The morulas carrying the reporter gene have normal $p 35$ alleles (confirmed by PCR) and have the $\mathrm{X}^{\text {lacZ }} / \mathrm{X}^{\text {lacZ }}$ or

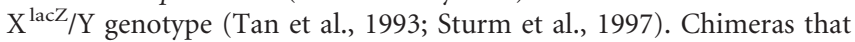
contain $p 35^{-I-}$ cells (identified by genotyping) were selected for the study, whereas chimeras with $p 35^{+/-}$cells were used as controls. Fused morulas were cultured overnight to the blastocyst stage before implanting into pseudopregnant foster females. Chimeric pups were reared until
15-18 d before genotype analysis, X-gal histochemistry, immunocytochemical analysis, and fluorogold injection into their brainstems.

To determine whether $p 35^{+/+}$and $p 35^{-1-}$ neurons migrate properly into their layer positions in the chimeric brain, mice were treated in utero [at embryonic day 12.5 (E12.5) or E16.5] with 5-bromodeoxyuridine (BrdU) at a dose of 50 or $100 \mu \mathrm{g} / \mathrm{mg}$ of body weight (i.p., dissolved in sterile saline containing $0.007 \mathrm{~N} \mathrm{NaOH}$ ). Neurons that contain the BrdU label are presumed born during the labeling period when they undergo their final cell division.

Genotyping. To isolate DNA for PCR genotyping, tissue (toe, tail, or liver) was digested in $200 \mu \mathrm{l}$ of PCR lysis buffer $(50 \mathrm{~mm} \mathrm{KCl}, 10 \mathrm{~mm}$ Tris- $\mathrm{HCl}, \mathrm{pH}$ $8.3,2 \mathrm{~mm} \mathrm{MgCl}, 0.45 \%$ Nonidet P-40, and $0.45 \%$ Tween 20 ) with proteinase $\mathrm{K}(200 \mu \mathrm{g} / \mathrm{ml})$ at $56^{\circ} \mathrm{C}$. DNA primers were used at a final reaction concentration of $10 \mathrm{ng} / \mu \mathrm{l}$. Primers for $p 35$ covering the deleted portion of the gene (Chae et al., 1997) and for the neomycin phosphotransferase (neo) gene were used ( $p 35$; forward 5'GGCAATGAAATCTCCTACCCG-3', reverse 5'-ACCCCAAGGAAAAGAACGTG-3', neo; forward 5' -ATCAGGATGATCTGGACGAAGA-3' and reverse 5'-CCACAGTCGATGAATCCAGAA-3'). Primer sequences for $l a c Z$ were as follows: lac $Z$ forward 5' -CCCATTACGGTCAATCCGCCG-3' and reverse 5'-CCTGGCCGTAACCGACCCAGCG-3'.

The DNA-primer mixture was heated at $94^{\circ} \mathrm{C}$ for $10 \mathrm{~min}$ in a Gene Amp PCR System (Model 9600; PerkinElmer Life Sciences, Emeryville, CA). A reaction mix was then added to give a final concentration of 100 mu Tris-HCl, pH 8.3, 500 mm KCl $(1 \times$ PCR Buffer II; PerkinElmer Life Sciences), $1.5 \mathrm{~mm} \mathrm{MgCl}_{2}, 100 \mu \mathrm{M}$ dNTPs, and 1.25 U TaqDNA polymerase (PerkinElmer Life Sciences). Amplification of the samples was performed by an additional $1 \mathrm{~min}$ at $94^{\circ} \mathrm{C}$ followed by 40 cycles consisting of annealing at $62^{\circ} \mathrm{C}$ for $30 \mathrm{sec}$, extension at $72^{\circ} \mathrm{C}$ for $30 \mathrm{sec}$, and denaturing at $94^{\circ} \mathrm{C}$ for $30 \mathrm{sec}$. PCR products were analyzed on a $2.5 \%$ agarose gel with anticipated $347 \mathrm{bp}, 170 \mathrm{bp}$, and $154 \mathrm{bp}$ product sizes for $p 35$, neo, and lac $Z$, respectively.

Histology. After a lethal injection of Rhompun and Ketavet, chimeras were perfused for $7 \mathrm{~min}$ by intracardial perfusion with $4 \%$ paraformaldehyde in $0.1 \mathrm{M}$ Sorensen's phosphate buffer, $\mathrm{pH} 7.4$, and the brains removed for $7 \mathrm{~min}$ postfixation. After cryoprotection with $20 \%$ sucrose, brains were embedded in OCT (Tissue-Tek, Torrance, CA) for cryosectioning. Coronal sections $(60 \mu \mathrm{m})$ of the cortex were obtained for X-gal histochemistry to visualize $\beta$-galactosidase $(\beta \mathrm{gal})$, and $14 \mu \mathrm{m}$ coronal sections were prepared for immunocytochemistry. Sections for X-gal histochemistry were incubated overnight at $37^{\circ} \mathrm{C}$ in a solution of $0.1 \%$ 4-chloro-5-bromo-3-indolyl- $\beta$-D-galactopyranoside (X-gal) containing $2 \mathrm{~mm} \mathrm{MgCl}_{2}, 5 \mathrm{~mm}$ EGTA, $0.01 \%$ (w/v) sodium deoxycholate, $0.02 \%$ (w/v) Nonidet P-40, $5 \mathrm{~mm} \mathrm{~K}_{3} \mathrm{Fe}(\mathrm{CN})_{6}$, and $5 \mathrm{~mm} \mathrm{~K}_{4} \mathrm{Fe}(\mathrm{CN})_{6} \cdot 6 \mathrm{H}_{2} \mathrm{O}$ in $0.1 \mathrm{M}$ Sorenson's phosphate buffer. The X-gal was prepared as a $4 \%$ stock in dimethylformamide and was added to the mixture just before use.

To reveal the nuclei of both mutant and wild-type cells, we used bisbenzimide staining. After X-gal histochemistry, sections were rinsed in PBS and then stained in $10 \mu \mathrm{g} / \mathrm{ml}$ of Hoescht 33342 (Sigma, Sydney, Australia) for $5 \mathrm{~min}$. Fluorescent cell nuclei were visualized using a UV filter (excitation filter, BP330-385).

Immunocytochemistry. For double immunofluorescence studies, 14 $\mu \mathrm{m}$ coronal sections were mounted on 3-aminopropyltreithoxy-silanecoated slides and dried for $2 \mathrm{hr}$ before incubating in primary antibodies. To obtain double labeling of $\beta$ gal with BrdU, neuronal-specific nuclear protein (NeuN), GABA, calbindin, T-brain (Tbr-1), or 2'3' '-cyclic nucleotide $3^{\prime}$-phosphodiesterase (CNPase), sections were processed for immunocytochemistry using either standard one-step or two-step avidinbiotin procedures. To expose the BrdU, tissues were preincubated with $2 \mathrm{~N} \mathrm{HCl}$ at $37^{\circ} \mathrm{C}$ for $45 \mathrm{~min}$ before addition of the primary antibody. All primary antibodies were diluted in $0.1 \mathrm{M}$ PBS with $0.3 \%$ Triton X-100. Primary antibodies included a purified rabbit polyclonal antibody to Bgal (1:1000 dilution; Capel; ICN Pharmaceuticals, Aurora, OH), a purified rabbit polyclonal antibody to $\beta$ gal (1:500; 5 Prime $\rightarrow 3$ Prime, Boulder, CO), a mouse monoclonal antibody to $\beta$ gal (1:250; Promega, Hawthorne, Australia), a mouse monoclonal antibody to $\operatorname{BrdU}$ (1:30; Becton Dickinson, San Jose, CA), a mouse monoclonal antibody to NeuN (1:200; Chemicon, Temecula, CA), a rabbit polyclonal to GABA (1:1000; Sigma), a mouse monoclonal antibody to CNPase (1:200; 
Chemicon), a rabbit polyclonal to $\mathrm{TBr}-1$ (1:125), a rabbit polyclonal antibody to empty spiracles (Emx-1) (1:5000 with tyramide signal amplification) (Hammond et al., 2001), and a rabbit polyclonal antibody to calbindin (1:1000; Swant, Bellinzona, Switzerland). Secondary antibodies were biotinylated anti-rabbit (1:200; Vector Laboratories, Burlingame, CA), Alexa Fluor 594-conjugated goat anti-mouse IgG (1:300; Molecular Probes, Eugene, OR), and Alexa Fluor 594-conjugated goat anti-rabbit IgG (1:500; Molecular Probes). With BrdU, NeuN, Tbr-1, Emx-1, and CNPase antigens, simultaneous visualization of $\beta$ gal was achieved with fluorescein-avidin D (1:200; Vector Laboratories). Incubation with primary antibody overnight was followed by $1 \mathrm{hr}$ in secondary antibodies before coverslipping with Fluoromount-G (Southern Biotechnology, Birmingham, AL).

For data quantification, we divided the cortical thickness into 21 bins (bin 1 is closest to the pial surface) and scored the number of neurons belonging to both genotypes in each bin $\left(p 35^{+/+}\right.$and $\left.p 35^{-1-}\right)$. For $p 35^{+/+}$neurons, we counted cells showing double immunofluorescence for $\beta$ gal and NeuN, whereas $p 35^{-1-}$ neurons stained for NeuN only. This process was repeated on $14 \mu \mathrm{m}$ coronal sections from three different chimeras. For strong chimeras, an area of $1170 \times 1500 \mu \mathrm{m}$ was surveyed, whereas in the weaker chimera, a smaller area of $470 \times 1500 \mu \mathrm{m}$ was selected to focus on the region containing wild-type cells.

To visualize layer $\mathrm{V}$ pyramidal neurons, the distal targets of their axons in the brain stem were injected with a $4 \%$ solution of fluorogold (Fluorochrome, Denver, CO) into postnatal day 15 (P15)-P18 animals $\left(p 35^{++}, p 35^{-1-}\right.$ mutants, $p 35^{-1-}$ chimeras). After recovery, animals were killed $2-3 d$ later by perfusion fixation. Coronal sections of the cortex were obtained, and the fluorogold label was revealed using a UV filter as well as with a rabbit polyclonal antibody to fluorogold (1:600; Fluorochrome). $\beta$ gal labeling of wild-type neurons in $p 35^{-1-}$ chimeras was revealed using $\beta$ gal immunocytochemistry. To assess the number of labeled layer $\mathrm{V}$ pyramidal neurons, we counted layer $\mathrm{V}$ mutant neurons (single-labeled with fluorogold) and wild-type neurons (double labeled with fluorogold and $\beta$ gal $)$ present in the cortex $(1170 \times 1500 \mu \mathrm{m}$ area $)$ of two chimeras.

\section{Results}

Chimeras were identified by their patchy coat colors resulting from the different coat color allele combinations used for morula aggregation. Genotyping was performed using toe tissue DNA, and nonchimeras were identified by the lack of a PCR product for lac Z (Fig. $1 B$, lanes 1-3), the distinguishing genotype of cells with wild-type $p 35^{+/+}$alleles. The presence or absence of $p 35$ or neo fragments allowed chimeras with $p 35^{+/+}$cells to be distinguished from chimeras with heterozygous $\left(p 35^{+/-}\right)$or null $\left(p 35^{-/-}\right)$ cells. Lanes 1, 2, and 3 do not have a lac $Z$ product and are hence considered to be nonchimeras. Toe DNA containing a smaller contribution by wild-type cells tended to provide a barely distinguishable $p 35$ band with a strong band for the neo gene contained in the targeting construct (Fig. 1 A, lanes 5,7,8) (Chae et al., 1997). Toe tissues containing a greater ratio of wild-type cells were recognized by a more intense band for $p 35$ together with the neo band (Fig. 1A, lanes 4,6). Using previously established criteria (Hammond et al., 2001), chimeras containing heterozygous $\left(p 35^{+/-}\right)$cells were distinguished by the presence of an even stronger $\mathrm{p} 35$ band compared with chimeras containing homozygous $\left(p 35^{-1-}\right)$ cells. This diagnostic method was developed after postgenotyping examination of brain phenotypes (presence or absence of a "supercortex"). Interestingly, there was no direct correlation between the degree of chimerism suggested by genotyping of toe DNA with the actual composition of mutant and wild-type cells in the cortex. Lane 9 in Figure 1 is from wild-type morulas only, showing the presence of the $p 35$ gene in these embryos.

From a total of 638 morula aggregation events, 196 pups were born and reared to postnatal stages. From these, we obtained 113

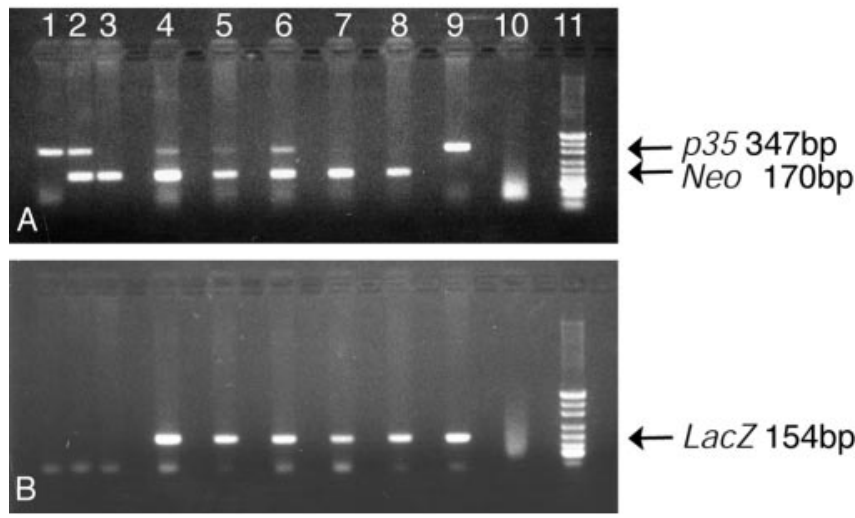

Figure 1. Genotyping using toe tissues to distinguish chimeric from nonchimeric animals and wild-type from mutant animals. $A$, Top band represents the endogenous allele ( $p 35$ $347 \mathrm{bp}$ ), and the bottom band represents the mutant allele (neo 170bp). B, LacZ band from introduced lacZ transgenic morulas (154bp). Lane 1, Wild-type ( $\left.p 35^{+/+}\right)$; lane 2, heterozygous mutant $\left(p 35^{+/-}\right)$; lane 3 , homozygous mutant $\left(p 35^{-/-}\right)$; lanes $4-8, p 35^{-/-}$chimeras; lane 9, lacZ transgenic morulas used to make chimeras; lane 10, no DNA; lane 11, pUCHpall markers. Chimeras containing a lesser contribution of wild-type cells in the toe biopsies (lanes $5,7,8)$ gave a strong neo band and a weak $p 35$ band; conversely, chimeras with greater contributions by wild-type cells in the biopsies (lanes 4,6 ) gave a stronger $p 35$ signal from the wildtype alleles. Confirmation of the presence of the wild-type cells was obtained by assaying for the presence of the lacZ transgene. As expected, this band was present in the lacZ transgenic morulas (lane 9) and in the chimeras (lanes 4-8).

chimeras (judging by their coat colors) and allocated them in three categories with respect to $\mathrm{p} 35\left(\mathrm{p} 35^{+/+} \leftrightarrow \mathrm{p} 35^{+/+}, n=32\right.$; $\left.p 35^{+/+} \leftrightarrow \mathrm{p} 35^{+/-}, n=73 ; p 35^{+/+} \leftrightarrow \mathrm{p} 35^{-/-}, n=8\right)$. For the purpose of the current study, we stopped killing animals after we identified the first eight chimeras in the homozygous category $\left(p 35^{+/+} \leftrightarrow \mathrm{p} 35^{-/-}\right.$) using the criteria of a weak p35 PCR band from toe tissue and the presence of a supercortex after histochemical staining. Other homozygous chimeras that were identified by PCR but not confirmed by morphological examination of their cortices were presumed to belong to the heterozygous category $\left(p 35^{+/+} \leftrightarrow \mathrm{p} 35^{+/-}\right)$.

\section{Wild-type cells in p35 $35^{-/-}$chimeras form a supercortex}

Littermates containing lac $Z$, together with cells containing $p 35^{+/+}$(wild type) or $p 35^{+/-}$(heterozygous) genotypes, were used as controls to rule out abnormalities arising from the experimental aggregation of different mouse lines. In these chimeras, $\beta$ gal-expressing cells in the neocortex exhibit cell dispersion patterns (data not shown) seen in normal chimeras reported previously (Tan et al., 1998). In addition, radial columns of $\beta$ galpositive cells extending across the full cortical depth are present in chimeras containing $p 35^{+/-}$neurons, suggesting that wildtype neurons migrate normally, despite an environment of $p 35$ heterozygous cells (data not shown). In contrast, the distribution of lacZ-expressing cells in $p 35^{-1-}$ chimeras is unusual, with ectopic segregation of $\beta$ gal-positive cells primarily in the top half of the cortex with a strong concentration of cells underneath the marginal zone (Fig. $2 A$; for a higher power view, see bracket in $B$ ). The organization of $\beta$ gal-positive cells into a band adjacent to the marginal zone resembles a supernumerary cortex, and, on this basis, we called this arrangement of wild-type neurons a supercortex (Hammond et al., 2001). This term was applied after the observation that the supernumerary cortex contains neurons of all six cortical layers (see below) with clear delineation of layerspecific cellular densities (Fig. 2 B). The territorial coverage of the supercortex occupies the dorsal half of the cortical depth (Fig. 2, 

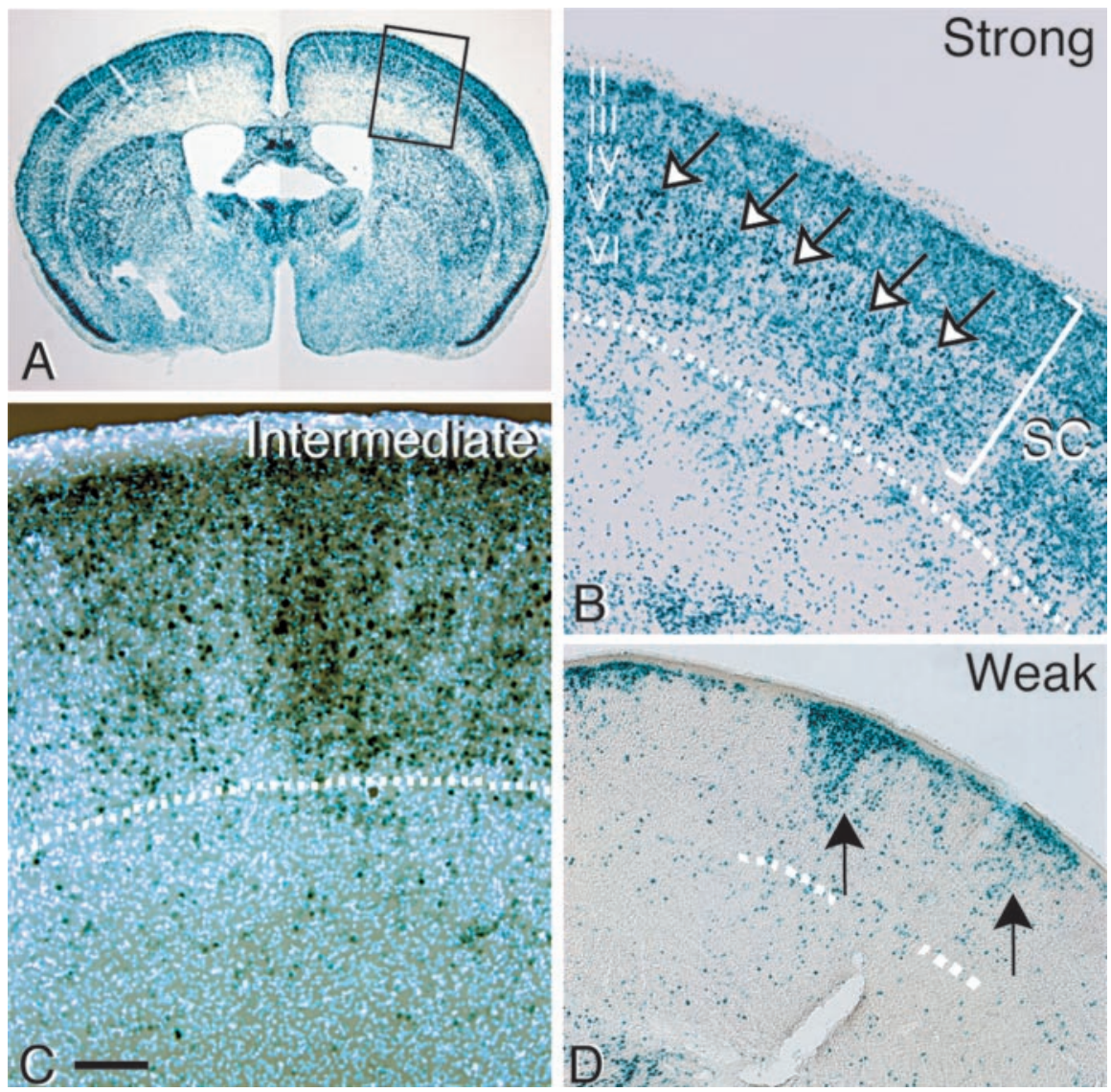

Figure 2. $\mathrm{p} 35^{+/+}$cells in chimeras form a supercortex (SC) beneath the pial surface. The supercortex is observed in chimeras regardless of strong, intermediate, or weak contribution by wild-type cells to the cortex. The supercortex typically occupies the dorsal half of the cortical depth, indicated by dotted lines. $A$, In this strong $p 35^{-1-}$ chimera, the top half of the cortex is occupied by a supercortex comprised of wild-type cells revealed by the presence of $\beta$ gal. Note that mutant cells ( $\beta$ gal negative) occupy the bottom half of the cortical depth. $B$, Higher magnification of boxed area in $A$, showing the arrangement of cells in the SC. Roman numerals indicate positions of different layers. Note that layer V pyramidal neurons with large cell bodies (arrows) are located in the appropriate position relative to the thickness of the supercortex. In addition, top layers appear to be more densely packed. $C$ Intermediate chimera at the supercortex/mutant cortex interface showing extensive infiltration of mutant cells (revealed by bisbenzimide staining) into the supercortex. A sprinkling of wild-type cells can be seen in the underlying mutant cortex. D, Weak chimera showing that $\beta$ gal-positive cells in the supercortex are organized into radial columns (arrows). Dotted lines represent the lower limit of columns formed by $\beta$ gal-positive cells. Scale bars: $A, 1400 \mu \mathrm{m} ; B, 200 \mu \mathrm{m} ; C, 160 \mu \mathrm{m} ; D, 400 \mu \mathrm{m}$.

\section{Distribution of wild-type and} p35 ${ }^{-1-}$ cells

The above results indicate that wild-type cells tend to segregate in the top half of the cerebral wall, whereas mutant $p 35^{-1-}$ cells tend to remain in the bottom half. This trend is similar to that reported for chimeras with $\mathrm{cdk} 5^{-/-}$cells (Gilmore and Herrup, 2001). To quantify how these observations relate to the degree of chimerism (strong or weak presence of wild-type cells), the genotype ratios of neurons present in different cortical levels were determined using previously established benchmarks (Gilmore and Herrup, 2001). These data are depicted in Table 1, in which the raw counts and relative percentages for three chimeras are tabulated for the distribution of wild-type neurons and mutant neurons. Both strong (TC18, TC40) and weak (TC90) chimeras show a strong tendency for wild-type neurons to be segregated in the top part of the cerebral wall (bins 1-10) (Table 1). There are some wild-type neurons present in the bottom half of the cerebral wall in bins 11-15, and these correspond to loosely scattered wild-type neurons observed in the mutant cortical environment. The above observations raise the question of whether the tendency to form a supercortex is dependent on the ratio of the two neuronal genotypes. This does not seem to be the case in the weaker chimera (TC90), which shows a relatively high mutant/ wild-type ratio in bins $1-10$, and yet the wild-type neurons in this chimera are also segregated in the top half. Thus, it would appear that the formation of a supercortex is not dependent on a linear relationship between the ratio of mutant to wild-type neurons, indicating that perhaps a mini-

dotted lines), and this thickness did not appear to vary among animals, regardless of a strong, intermediate, or weak contribution by $\beta$ gal-positive cells (Fig. $2 B-D$, respectively). With the exception of the cingulate and piriform cortex where the structure is much thinner, the supercortex is uniformly distributed in the mediolateral axis. At approximately midlevel in the supercortex, darker $\beta$ gal-positive cell bodies may be discerned; their size and arrangement would suggest them to be layer $\mathrm{V}$ pyramidal neurons (Fig. $2 B$, arrows). Mutant $p 35^{-1-}$ cells (revealed by bisbenzimide staining as white fluorescent nuclei) are also present in the top half but only less so compared with the bottom half, and they appear to be interspersed with $\beta$ gal-positive cells (Fig. 2C). Most mutant cells are concentrated in the bottom half of the cortical depth where a smaller number of $\beta$ gal-positive cells are diffusely intermingled with $p 35^{-1-}$ cells (Fig. $2 B, C$ ). $\beta$ galpositive cells in the supercortex appear to be organized into radial columns, which is most evident in weaker chimeras where columns could be distinguished (Fig. $2 D$, arrows). Unlike mutants of the Reelin-signaling pathway, the marginal zone appears to be correctly developed with no evidence of excessive cellular infiltration. mum threshold of closely packed neurons may be sufficient. Of further interest is the observation that mutant cells formed the majority of cells in all chimeric cortices examined, and this bias was also seen in toe tissues (Fig. 1). The precise reason for the selective disadvantage of wild-type neurons in the cortex is unclear but one possibility is that wild-type neurons are less likely to proliferate or survive in a mutant cortical landscape where neurons are malpositioned and fibers infiltrate aberrantly.

\section{P35 ${ }^{+/+}$cells in the supercortex consist of both pyramidal and nonpyramidal neurons}

To determine the identity of the cells making up the supercortex, we performed double-immunofluorescent experiments using antibodies against $\beta$ gal (to mark wild-type cells) and NeuN, a general marker for neurons. Mutant neurons lack $\beta$ gal and would be immunoreactivity only for $\mathrm{NeuN}$ (Fig. $3 A$, red), whereas double-labeled cells (Fig. $3 A$, yellow) would indicate the positions of wild-type neurons. The results indicate that the majority of cells in the supercortex are a mixture of wild-type and $p 35^{-1-}$ mutant neurons (Fig. 3A). A small number of cells (presumably glia) expressed $\beta$ gal (Fig. $3 A$, green) but did not stain with NeuN 
Table 1. Number and distribution of $\mathrm{p} 35^{+/+}$and $\mathrm{p} 35^{-/-}$neurons in chimeric cortices

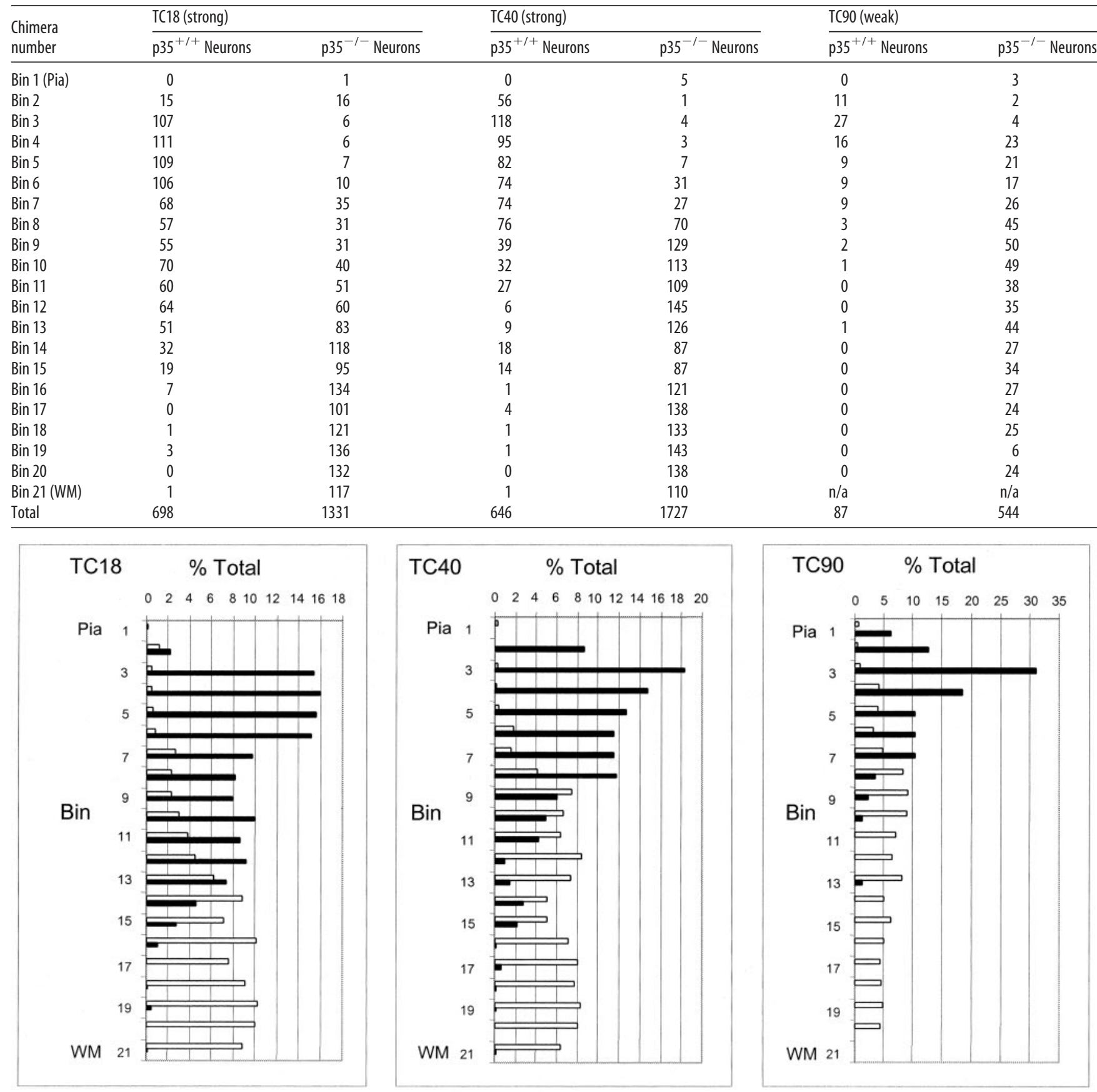

\section{p35+/+ Neurons ap35-/- Neurons}

Neurons belonging to different genotypes were assigned into bins that subdivide the cortical thickness. Double immunofluorescence for Bgal and NeuN was used to identify p35 $+/+$ neurons, whereas p35 - - neurons did not stain for Bgal (see Materials and Methods).

(Fig. 3A, arrowheads). A higher power view $(20 \times)$ of the supercortex shows that almost every NeuN-positive neuron in the top layers of the supercortex is wild-type, whereas the lower layers are composed of a mixture of both mutant neurons (Fig. 3B, circles) mixed in among wild-type neurons (Fig. $3 B$, arrows). These lower layer neurons possess large cell bodies with pyramidal shapes. Their relatively deep positions and large somas sizes would suggest them to be layer V pyramidal neurons. To confirm their pyramidal identity, we used antibodies against Emx-1, a homeodomain transcription factor previously shown to be a marker for pyramidal neurons (Chan et al., 2001). This shows that not only layer $\mathrm{V}$ but that the majority of cells in the supercortex are double labeled for $\beta$ gal and Emx-1 (Fig 3C,D, yellow), indicating that the bulk of wild-type neurons that migrate into this location are pyramidal in character. Additional confirmation is provided by double staining for $\beta$ gal and Tbr-1, a putative transcription factor that labels pyramidal neurons in layers III and VI (Hevner et al., 2001), and this shows that $\beta$ gal/Tbr-1positive neurons are found in positions corresponding to layer III of the supercortex (Fig. 3E, yellow). As mentioned above, the bottom layers of the supercortex also contain a large number of mutant pyramidal neurons that stained for Emx-1 only (Fig. 3D, 

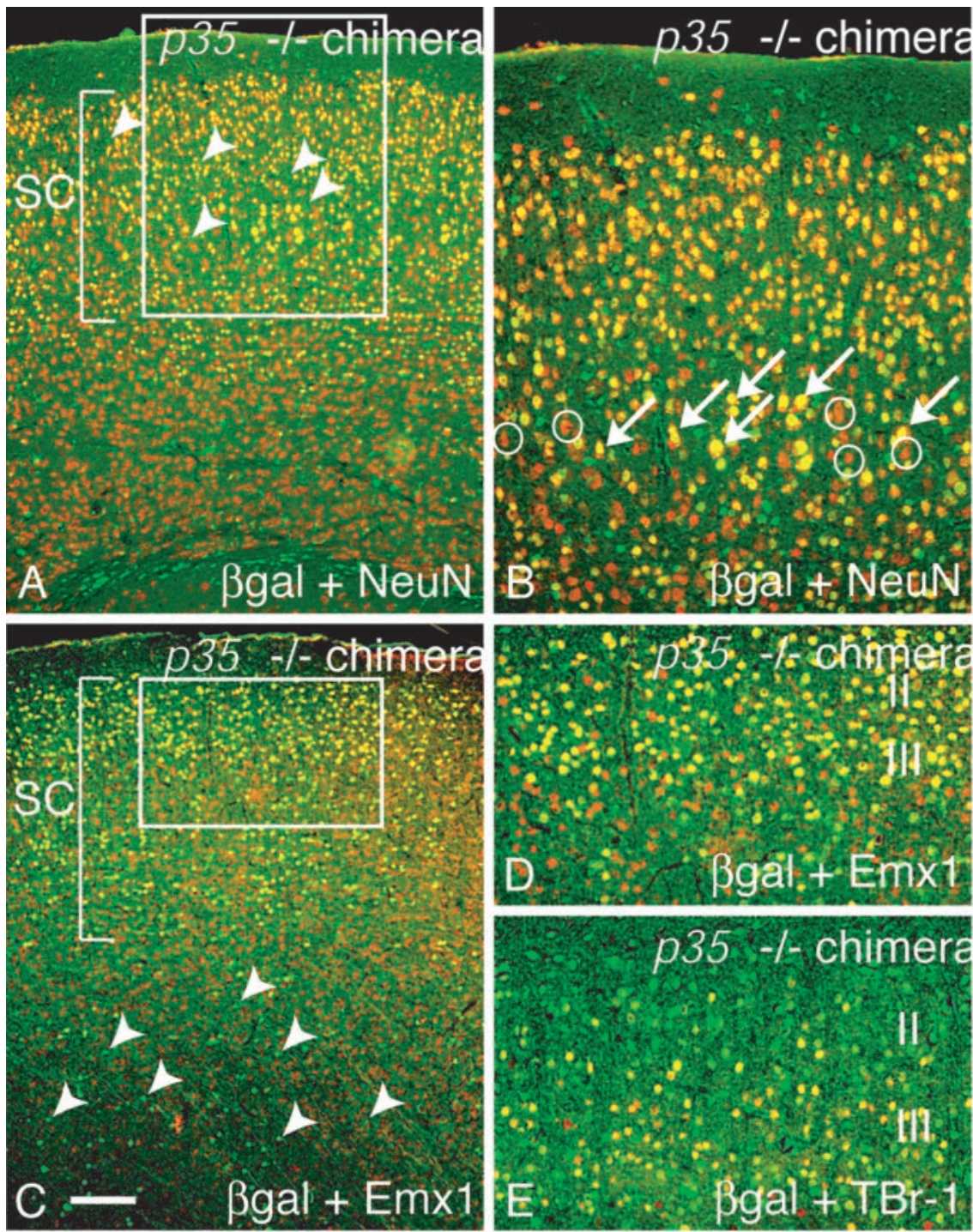

Figure 3. $\mathrm{p} 35^{+/+}$cells in the supercortex are primarily pyramidal neurons. $A$, Double labeling for $\beta$ gal (green) and NeuN (red) reveals that the vast majority of $p 35^{+/+}$cells in the supercortex (SC) are neurons (yellow or orange). A small number of cells (presumably glia) expressed $\beta$ gal (green) but not NeuN (arrowheads). $B$, Higher magnification of boxed area in $A$, indicating that the vast majority of neurons in the top layers (II, III) of the supercortex are wild type (double labeled), whereas those in the bottom layers (IV, V, VI) are a mixture of wild type (yellow) and mutant (red, circles). C, $p 35^{+/+}$neurons in the SC are double labeled for $\beta \mathrm{gal}$ (green) and Emx1 (red), a marker of pyramidal neurons. In this chimera, most $\beta$ gal-positive cells also express Emx 1 (yellow); however, the supercortex also contains large numbers of mutant pyramidal neurons that also stain for Emx 1 (red) and a small number of $\beta$ gal-positive cells that are Emx1 negative (green). These Emx1-negative neurons are likely to be nonpyramidal and are also found in large numbers in the mutant cortex lying below the supercortex (green, arrowheads). D, Higher magnification of boxed area in C, confirming that the majority of wild-type cells in layers II and III stain for Emx 1 and are therefore pyramidal neurons. E, Additional confirmation of the pyramidal nature of supercortex neurons was obtained by double labeling for Tbr-1 (yellow), a marker for layers III and VI pyramidals. Scale bars: $A, C, 160 \mu \mathrm{m} ; B, D, E, 80 \mu \mathrm{m}$.

red). Conversely, we also encounter $\beta$ gal-positive cells that are Emx-1 negative. These neurons are likely to be nonpyramidal and are also found in the mutant cortex lying below the supercortex (Fig. 3C, arrowheads). Interestingly, although wild-type cells are frequently seen in the mutant cortex, these invariably failed to stain for either NeuN or Emx-1 (Fig. 3A,C), suggesting that they are mostly glia or nonpyramidal neurons.

To further investigate the distribution of the nonpyramidal population, double immunofluorescence was conducted using antibodies to $\beta$ gal and GABA, a marker for interneurons. The results show that interneurons of both genotypes are present in the supercortex (Fig. $4 A, B, p 35^{+/+}$yellow, arrows; $p 35^{-/-}$red, circles). A higher power view $(20 \times)$ shows that mutant interneurons are diffusely scattered within the supercortex (Fig. $4 B$, red, circles). Furthermore, mutant GABA interneurons are also diffusely scattered throughout the entire cortical depth, including the mutant cortical space (Fig. $4 A$, circles). These observations indicate that, regardless of whether GABAergic neurons are $p 35^{-/-}$or $p 35^{+/+}$in genotype, they have no problems infiltrating both the supercortex and underlying mutant cortex.

Aberrant fiber defasciculation is present in mutant cortex but not in supercortex It has been shown previously, using silver staining, that brains from $p 35^{-1-}$ mice have aberrant fiber fascicles in the cortex (Chae et al., 1997). Additional investigations indicate a failure of the projection cortical axons to assimilate into the corpus callosum, instead they take an oblique path to the midline, cross the midline, and exit in an oblique path through the cortical hemisphere (Kwon et al., 1999). Therefore, it would be of interest to examine the fiber patterns in chimeric cortices to examine the influence of a properly layered supercortex within the mutant cortical wall. To stain myelinated fibers, an antibody was used against the myelinassociated enzyme CNPase. In the normal cortex, CNPase immunoreactivity is associated only with myelin-producing cells found in deeper layers and also in the white matter (Vogel et al., 1988). Staining of the mutant $p 35^{-/-}$confirmed the presence of aberrant myelinated fiber fascicles in the mutant cortex, and, in particular, thick fiber tracts are found in the bottom two-thirds of the cerebral wall (Fig. 4C). In the chimeric cortex, fiber fascicles are seen to persist in the mutant cortical compartment, whereas the overlying super cortex that contains both mutant and wild-type cells shows almost no CNPase immunoreactivity in the top layers (Fig. $4 D$ ). Thus, it would appear that the presence of a properly layered cortical structure made up of wild-type cells is associated with normal fiber fasciculation. A mild degree of myelination persists in the deeper layers of the supercortex, but this is comparable with myelination of normal wild-type cortices (results not shown).

\section{Wild-type but not mutant neurons are correctly layered} Mice lacking the $p 35$ gene exhibit inverted cortical layers causing the earlier-born neurons to be misplaced underneath the pial surface, whereas later-born neurons are localized deep next to the white matter (Chae et al., 1997; Kwon and Tsai, 1998). If p35 activity has a non cell autonomous effect with respect to neuronal layering, one may expect to observe occasional rescue of the mutant layering phenotype. Conversely, a mutant cortical environ- 
ment resulting from deficient p35 activity should cause wild-type neurons to assume inappropriate layer positions. To investigate these possibilities, layering order was explored using two different techniques: calbindin staining and BrdU birthdating.

First, we used antibodies against the calbindin neuropeptide, which within the pyramidal neuron population is known to stain only the supragranular layers (II and III) (Demeulemeester et al., 1989; van Brederode et al., 1991). In the $p 35^{-/-}$mutant, layer inversion causes the calbindinlabeled neurons (with associated labeled neuropil) to be segregated to the deeper aspects of the cortical wall next to the white matter (Fig. 5A, green, bracket). Other diffusely scattered calbindinpositive neurons with intensely stained cell bodies and cellular processes are also present, but these are believed to belong to the interneuron population (Gonchar and Burkhalter, 1997; Hammond et al., 2001) (Fig. $5 A$, arrowheads). In $p 35^{-1-}$ chimeras, the mutant calbindin-stained cells also assume an inverted layer II/III location, deep next to the white matter (Fig. 5B, green, bracket). In addition, there is a second region of calbindin staining (also associated with fluorescent neuropil) in the supercortex just underneath the marginal zone (Fig. $5 B$, double labeled, yellow, arrows). The majority of cells in this region are clearly double labeled with $\beta$ gal and calbindin, suggesting that wild-type layer II/III pyramidal neurons have positioned themselves correctly within the supercortex.Between the two calbindin-positive regions, there are numerous calbindin-positive interneurons of both genotypes (Fig. $5 B$, arrowheads).

The second line of evidence in support of cell-autonomous neuronal layering was obtained by tracking the positions of neurons labeled during the last round of cell division with the thymidine analog BrdU. This was performed for both $p 35^{-/-}$mutants and $p 35^{-1-}$ chimeras at times when deep layer neurons are born at E12.5 and superficial layer neurons at E16.5. In p $35^{-1-}$ chimeras, BrdU injection at E12.5 shows labeling of wild-type neurons in the bottom layers of the supercortex (Fig. 5C, yellow, arrows), which is compatible with the expected labeling position of early-born neurons. Injection of BrdU at E16.5 produced the opposite result with double-labeled wild-type cells ending up in the top layers of the supercortex (Fig. $5 D$, arrows). Together, these results indicate that wild-type neurons born at different times in the chimeric cortex have migrated to their appropriate deep and superficial layer positions within the supercortex. Supporting data from layer-specific staining with calbindin antibodies (layers II and III) and Tbr-1 antibodies (layers III and VI) (Fig. 3E) provide additional evidence that neuronal positioning of wild-type cells in the supercortex appears to be independently driven and correlated with the $p 35^{+/+}$genotype.
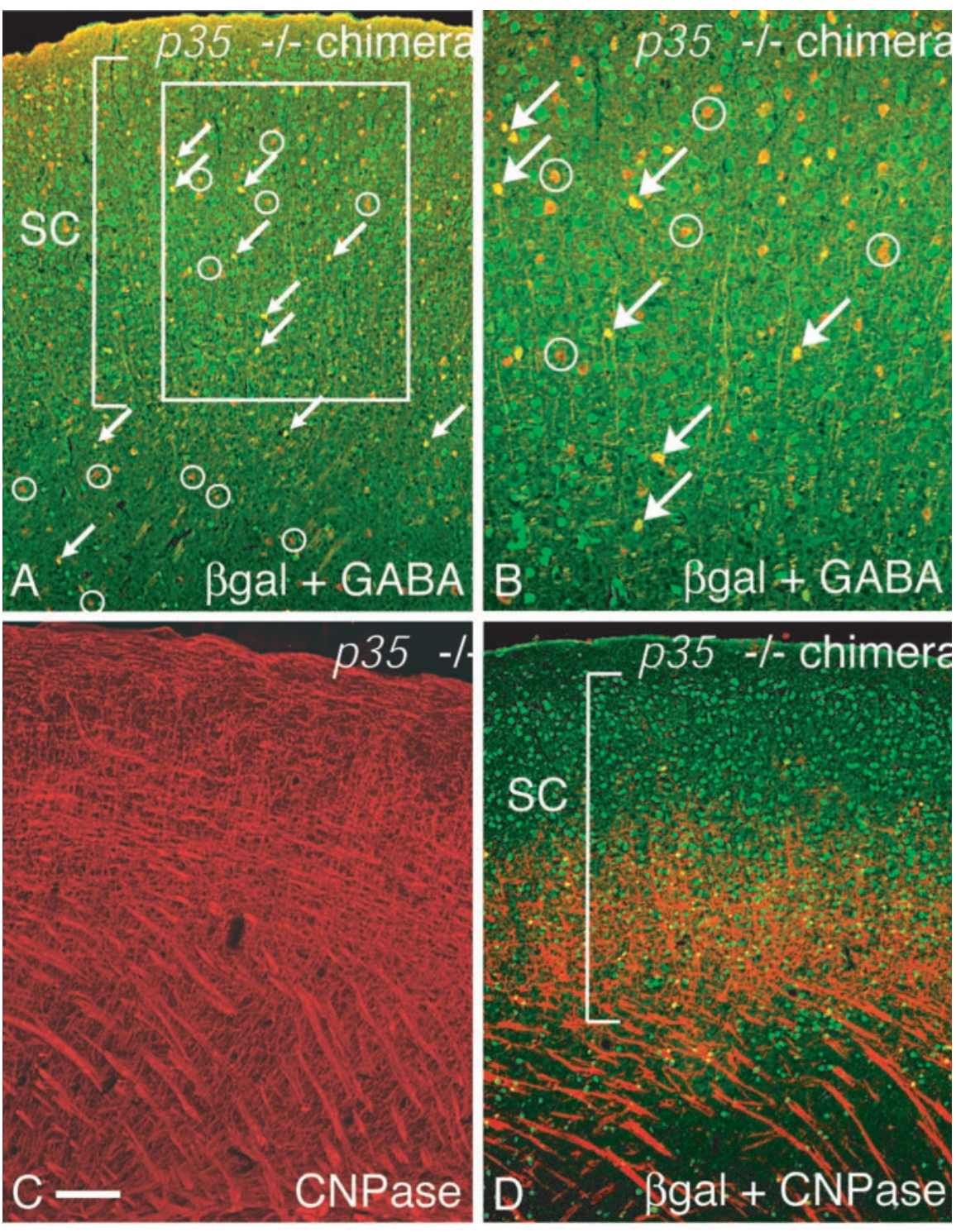

Figure 4. The supercortex contains GABAergic interneurons of both genotypes and shows absence of aberrant fibers in the top layers. $A$, Double immunofluorescence for $\beta$ gal (green) and GABA (red) reveals that many double-positive cells (red with yellow center, arrows) are found in the supercortex, and a smaller number are visible beneath, in the mutant cortex. Mutant GABAergic neurons (circles) are also scattered throughout both wild-type and mutant regions. $B$, Higher magnification of boxed area in $(A)$ showing that GABA-positive interneurons of both genotypes, wild type (red with yellow center, arrows) and mutant (red, circles) are present in the supercortex. $C$, In $p 35^{-1-}$ mutant brains, CNPase immunoreactivity reveals abnormal distribution of thick myelinated fiber bundles and disoriented fine fibers throughout the entire cortical thickness. $D$, In $p 35^{-1-}$ chimeras, the top layers of the supercortex are free from CNPase staining, whereas disoriented fiber bundles are seen to persist in the mutant cortex and bottom parts of the supercortex (SC). Scale bars: $A, C, D, 160 \mu \mathrm{m} ; B, 80 \mu \mathrm{m}$.

The above notwithstanding, BrdU labeling of E12.5 chimeras also revealed some $p 35^{+/+}$neurons to be localized underneath the supercortex (Fig. 5C). Most likely, they are wild-type neurons that failed to be integrated into the supercortex. In addition, $p 35^{-1-}$ neurons labeled with BrdU at E12.5 are occasionally encountered within the supercortex (Fig. $5 C$, circled). Conversely, p35 $5^{-1-}$ neurons labeled with BrdU at E16.5 are also inverted in positions, adjacent to the white matter (results not shown).

\section{Mutant layer $\mathrm{V}$ pyramidal neurons are rescued in the supercortex}

Layer V pyramidal neurons typically have large cell bodies and are easily recognized by their characteristic pyramidal morphology with a large prominent apical dendrite (Feldman, 1984). These 


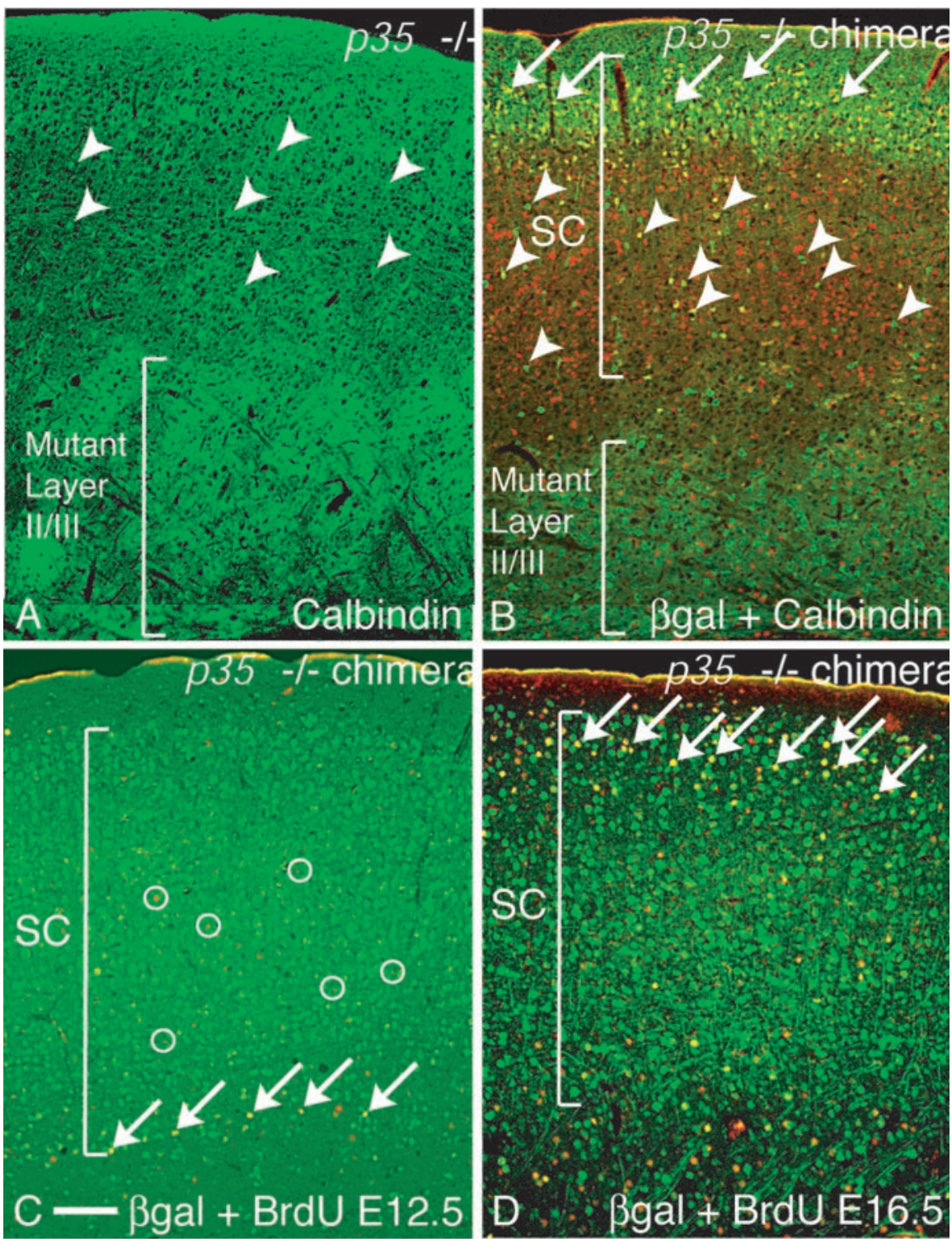

Figure 5. Wild-type but not mutant neurons are correctly layered in the $p 35^{-1-}$ chimeric cortices. $A$, In the cortex of mice lacking $p 35$, the supragranular pyramidal neurons of layers II and III (marked by calbindin) are found close to the white matter (bracket). Other diffusely scattered calbindin-positive neurons with intensely stained cell bodies (arrowheads) mark elements of the interneuron population. $B$, In the cortex of the $p 35^{-1-}$ chimera, calbindin-positive cells of wild-type genotype (yellow, arrows) belonging to layers II and III are seen in the top part of the supercortex (SC). In reverse, the equivalent mutant population stained with calbindin (green, bottom bracket) is found close to the white matter. Scattered interneurons of both genotypes can also be seen (arrowheads). C, Double labeling with $\beta$ gal (green) and BrdU (red) in $p 35^{-/-}$chimeras injected with BrdU at E12.5 shows the correct positioning of early-born wild-type neurons in the bottom layers of the supercortex (yellow, arrows). In addition, mutant neurons labeled at E12.5 with inverted positions are distributed within the supercortex (red, circles) Conversely, chimeric brains injected at E16.5 show double-labeled neurons (yellow, arrows) concentrated in the top layers of the supercortex $(D)$. Mutant neurons belonging to this cohort are inverted in position close to the white matter (data not shown). Scale bars: $A, B, 160$ $\mu \mathrm{m} ; C, D, 128 \mu \mathrm{m}$.

features may be revealed after retrograde labeling by introducing a fluorescent marker into their distal axonal targets in the brainstem. In control animals, injection of a fluorogold tracer into the brainstem of adult mice reveals a tight band of closely packed pyramidal neurons in the appropriate layer V location (Fig. 6A). At higher power, these fluorescent cell bodies are seen with prominent apical dendrites that are oriented toward the pial surface (Fig. 6A, inset, arrowheads). In the $p 35^{-1-}$ mutant, the retrograde-labeled layer $\mathrm{V}$ neurons are situated in their "insideout" position underneath the pial surface (Fig. $6 \mathrm{~B}$ ). Their cell bodies are loosely distributed, resulting in poor layer definition; however, in terms of mediolateral distribution, they appear to be of uniform depth. Although their apical processes can be recognized, they appear to be haphazard in orientation (Fig. 6B, inset), in agreement with previous descriptions (Chae et al., 1997). Note that, despite their malpositions, these mutant layer $\mathrm{V}$ neurons are able to make corticobulbar projections to the brainstem.

The position and orientation of layer $\mathrm{V}$ pyramidal neurons in the $p 35^{-/-}$chimera indicates non cell-autonomous behavior. In these brains, the supercortex can be revealed by $\beta$ gal immunostaining (Fig. $6 C$, red), and simultaneous detection of layer $\mathrm{V}$ neurons was performed using retrograde fluorogold labeling (Fig. 6C,D, green). Their retrograde label indicates that both wild-type (green with yellow center) and mutant (green) layer $\mathrm{V}$ neurons have functional projections to the brain stem. Although the wild-type layer V neurons are appropriately positioned within the correct layer of the supercortex, the mutant layer $\mathrm{V}$ neurons are situated at two different locations. One group of mutant neurons is arranged in a tight band together with the wild-type layer $\mathrm{V}$ neurons and, like wild-type neurons, they possess radially oriented apical dendrites (Fig. 6D, arrows). A second group of mutant layer $\mathrm{V}$ neurons is positioned at the periphery of the supercortex; here, they are loosely distributed and clearly disoriented with respect to their apical dendrites (only dendrites within the plane of focus are shown) (Fig. 6D, arrowheads). These results indicate successful rescue of some but not all of the mutant layer $\mathrm{V}$ neurons, and the rescued neurons appear to be assimilated into the correct layer of the supercortex. Unrescued neurons remain outside the border of the supercortex. The conditions giving rise to layer $\mathrm{V}$ neuron rescue are unclear, and it is possible that nonspecific environmental effects provided by a wild-type supercortex could mediate the rescue. To investigate this possibility, we looked into another type of chimera wherein a supercortex is also present in the same superficial location and layered correctly (Hammond et al., 2001). In these Dab1 $1^{+/+}$ $\leftrightarrow \mathrm{Dab}^{-1-}$ chimeras, the mutant neurons lack the Dabl gene, and the mutant neurons are layered incorrectly. After the backfilling of layer $\mathrm{V}$ neurons by fluorogold injections into the brainstem, the positions of both mutant and wild-type neurons are revealed (Fig. $6 E, F$ ). In contrast to the $p 35^{-l-}$ chimeras, these $D a b 1^{-1-}$ chimeras did not show rescue of the mutant layer $\mathrm{V}$ pyramidal neurons (Fig. $6 E$, red), which are haphazardly distributed beneath the supercortex (Fig. $6 F$, arrows). At higher magnification, backfilled neurons in the supercortex are invariably 
composed of wild-type neurons (Fig. 6F, red with yellow center, arrowheads). Hence, it would appear that malpositioned layer $\mathrm{V}$ neurons (in this instance from the $D a b 1^{-1-}$ genotype) are not automatically rescued by the presence of a correctly layered cortical environment.

Finally, we investigated the possibility that the degree of rescue may be related to the number of wild-type layer $\mathrm{V}$ neurons present in the vicinity. This was performed by quantifying the relative proportions of mutant versus wild-type layer $\mathrm{V}$ pyramidals inside and outside the supercortex (Table 2). Bearing in mind that this approximation is dependent on the efficiency of retrograde axonal labeling, we did not find a quantitative correlation between the degree of rescue and the number of wild-type neurons present. For instance, TC109 showed a relatively lower number of wild-type neurons, yet it contained a higher proportion of rescued mutant neurons.

\section{Discussion}

Genetic mosaics offer an excellent way of analyzing complex gene functions by exposing cells of different genotypes to a common developmental arena. In this study, we constructed chimeras composed of mutant $p 35^{-/-}$and wild-type $p 35^{+/+}$ cells to distinguish cell-autonomous from non cell-autonomous gene activities and to reveal any lineage-specific gene rescue. Using $\beta$ gal as an independent genetic marker for wild-type cells, we find that the migratory defects posed by the absence of p35 are partially rescued but only for earlier-generated neurons such as the layer $\mathrm{V}$ pyramidals. Late-born neurons, such as those destined for layers II and III neurons, failed to be rescued from their inverted positions. Nonetheless, the effects of p35 function and malfunction with respect to lamination are predominantly cell autonomous. This conclusion is supported by the observation that in these composite cortices, the two populations are set apart with most mutant $p 35^{-1-}$ neurons forming an inverted cortex, whereas the wild-type $p 35^{+/+}$neurons formed correctly layered supercortex. The fact that a supercortex was detected in both strong and weaker chimeras, even when mutant neurons are present in relatively large numbers in weak chimeras, would suggest that a threshold rather than a linear mechanism is responsible for the segregation of the wild-type neurons to the top compartment. Interestingly, aberrant fibers usually present in the $p 35^{-1-}$ null
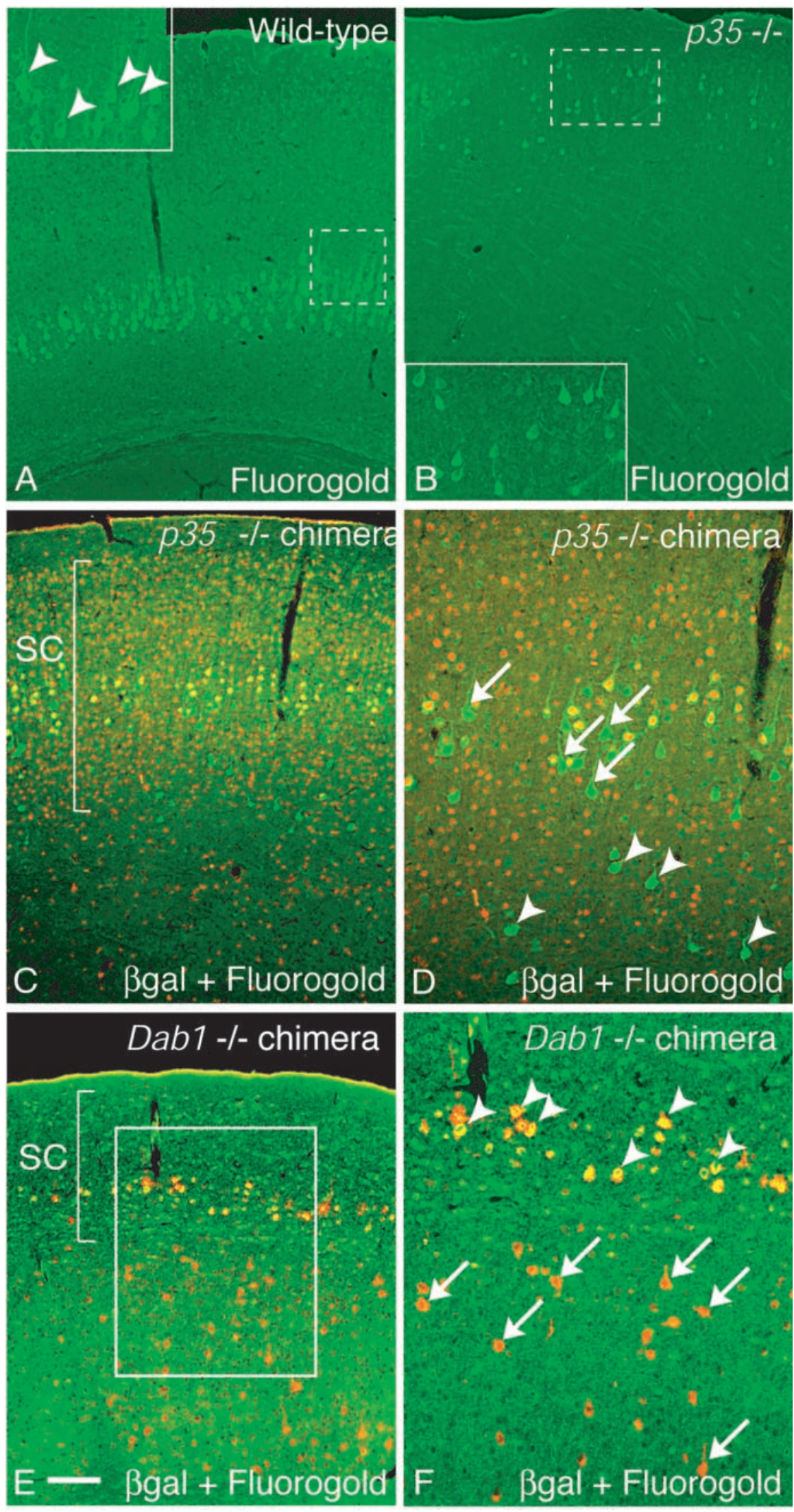

Figure 6. Mutant layer V pyramidal neurons labeled by retrograde fluorogold tracings are rescued in position and orientation. $A$, In the wild-type cortex, retrograde labeling of layer $V$ pyramidal neurons after fluorogold injection into the brainstem reveals brightly fluorescent cell bodies with prominent apical dendrites (insert, arrowheads). B, In the cortex of mice lacking $p 35$, layer V pyramidals are situated in their inside-out position near the pial surface. Although their apical dendrites are recognizable, their orientation is haphazard (insert). C, In $p 35^{-1-}$ chimeras, mutant layer V pyramidals (Figure legend continues) 
Table 2. Proportions of fluorogold-labeled wild-type and mutant layer $\mathbf{V}$ neurons situated inside and outside the supercortex

\begin{tabular}{|c|c|c|c|c|}
\hline \multirow[b]{2}{*}{ Chimera } & \multicolumn{2}{|c|}{$\begin{array}{l}\text { Layer V pyramidals inside } \\
\text { supercortex }\end{array}$} & \multirow{2}{*}{$\begin{array}{l}\text { Layer V pyramidals } \\
\text { beneath supercortex } \\
\text { Mutant (unrescued) }\end{array}$} & \multirow{2}{*}{$\begin{array}{l}\text { Percentage of } \\
\text { pyramidals } \\
\text { rescued } \\
\text { Mutant }\end{array}$} \\
\hline & Wild-type & Mutant (rescued) & & \\
\hline TC18 & 48 & 15 & 15 & 50.0 \\
\hline TC109 & 16 & 53 & 21 & 71.6 \\
\hline
\end{tabular}

Rescued neurons are found in the same positions as wild-type layer $V$ neurons with apically oriented dendrites. Unrescued mutant neurons are disoriented and situated beneath the supercortex.

mutant are rescued in the environment of the supercortex made up by wild-type neurons. These observations would suggest that p35-mediated signaling during cortical development has differential effects on neurons belonging to different layers, and certain mutant phenotypes may be rescued by non cell-autonomous mechanisms.

\section{Autonomous versus non autonomous behavior}

The cell-autonomous behavior for the majority of neurons with respect to $p 35$ genotype is not totally unexpected. Available evidence suggests that the main function of $\mathrm{p} 35$ in postmitotic neurons is to activate Cdk5, a serine-threonine kinase known to phosphorylate a number of substrates critical for neuronal development, including mDab1, NUDE-like, postsynaptic density 95, and neurofilament proteins (Shetty et al., 1993; Niethammer et al., 2000; Sasaki et al., 2000; Keshvara et al., 2002; Patzke et al., 2003). At the cellular level, Cdk5 is important for neurite extension, cell adhesion, and axonal transport (Nikolic et al., 1996; Kwon et al., 2000; Sasaki et al., 2000). Given their obligate relationship, functional studies with $\mathrm{p} 35$ become a proxy for Cdk5 at least in neurons where $\mathrm{p} 35$ is the main activator. Indeed, mutant mice for these two molecules share similar, although not identical, cortical phenotypes, including neuronal layer inversion, clumping of cell bodies, and abnormal infiltration of axonal tracts (Chae et al., 1997; Gilmore et al., 1998). The current study provides further demonstration that $\mathrm{p} 35 / \mathrm{Cdk} 5$ activation is linked to cell-autonomous behavior of pyramidal cortical neurons but not GABAergic interneurons during migration and layering. In addition, restoration of fiber morphology is linked only to top parts of the supercortex, where there are almost exclusively wild-type neurons. The arrangement of the chimeric cells indicates that proper neuronal migration (including the formation of radial columns) and layering is dependent on the $p 35^{+/+}$genotype, and, conversely, mutant $p 35^{-1-}$ neurons do not assemble themselves into the typical inside-out pattern of cortical layering. The fact that the vast majority of wild-type cells are positioned in the top compartment (forming a supercortex) and the mutant cells in the lower would suggest that neurons belonging to two separate genotypes are not capable of proper integration, although they share the same developmental space. The segregation is not absolute, because wild-type neurons are occasionally

\footnotetext{
Figure 6. (green) appear in two different locations. One group is observed in the bottom layers of the supercortex (SC) mixed among the wild-type double-labeled layer V pyramidals (double labeled, green with yellow center) and the other group (green) appears at the periphery beneath the supercortex. D, Higher magnification of boxed area in ( shows that, like their wild-type neighbors, the mutant layer $V$ neurons are correctly positioned and possess radially orientated apical dendrites (arrows). In contrast, mutant layer $V$ pyramidals lying in the mutant cortex are loosely distributed and disoriented (arrowheads). E, For comparison, retrograde-labeled layer V pyramidals in $D a b 1^{-1-}$ chimeras are invariably wild-type (double labeled, red with yellow center), and the mutant back-filled neurons (red) remain scattered beneath in the mutant cortex. F, Higher magnification of boxed area in $E$, showing wild-type layer $V$ pyramidals in the supercortex (red with yellow center, arrowheads) and the mutant neurons beneath (red, arrows). Scale bar: $A, B, 192 \mu \mathrm{m}$; insets, $96 \mu \mathrm{m} ; C, E, 192 \mu \mathrm{m} ; D, F, 96 \mu \mathrm{m}$.
}

encountered in the mutant cortical space, and, conversely, mutant cells are found in the supercortex. These exceptions to the rule suggest a possible influence of the environment on migrating cortical neurons regardless of their $p 35$ genotypes and, in this regard, non cell-autonomous behavior cannot be totally excluded. There are of course additional reasons including the possibility of defective radial glia caused by the $p 35$ mutation. Postmitotic neurons are known to detach from their parental glia moving sideways to adjacent glial processes (A. Kriegstein, personal communication). Thus, wild-type neurons that are attached to defective radial glial processes may be at a migratory disadvantage, causing them to be marooned in the mutant cortex. This interpretation is consistent with observations in the cerebellum of $C d k 5^{-1-}$ chimeras where granule cell positions were observed to have mixed outcomes. In these chimeras, the granule cells exhibit dichotomous phenotypes, with some $C d k 5^{-l-}$ granule cells marooned in the molecular layer, but other $C d k 5^{-1-}$ granule cells were able to migrate successfully to the internal granule layer (Ohshima et al., 1999). Thus, in both the cortex and cerebellum, p35/Cdk5 signaling may have subtle consequences for the way that migrating neurons interact with one another. The nature of these interactions is unclear, but cell-cell adhesion may be involved. Alterations in cell adhesive properties are known to be regulated by p35/Cdk5 activity (Homayouni and Curran, 2000; Kwon et al., 2000; Gao et al., 2002; Negash et al., 2002), and differential cell-cell adhesion could account for some of the observed separation of mutant and wild-type neurons in the $p 35^{-1-}$ chimeras.

Additional evidence for non cell-autonomous activity is provided by the rescue of mutant layer $\mathrm{V}$ pyramidal neurons lying in the supercortex in relation to layer position and neuronal orientation. However, neurons lying outside the supercortex remained unrescued and disoriented, suggesting that rescue may be dependent on the presence of a correctly layered cortical scaffold provided by a wild-type environment. It would seem that the presence of a supercortex per se is insufficient to rescue the malpositioned neurons. For example, $\mathrm{Dab1}^{+/+} \leftrightarrow \mathrm{Dab1}^{-/-}$chimeras also possess a supercortex; however, unlike the $p 35^{-1-}$ chimeras, all retrogradely labeled mutant neurons are distributed beneath the supercortex. This would suggest, but not prove, that rescue of mutant layer $\mathrm{V}$ neurons in the $p 35^{-1-}$ chimeras is specific to conditions associated with proper functioning of the $p 35$ gene. In addition, we failed to detect a straightforward linear relationship between the degree of rescue and the number of wild-type layer $\mathrm{V}$ neurons. So far, we confined our discussion to layer $\mathrm{V}$ neurons because it is possible to identify them unequivocally after retrograde dye labeling, large pyramidal-shaped somas, and prominent apical dendrites. In addition, their layer address in the supercortex matches that of wild-type layer $\mathrm{V}$ neurons that are also retrogradely labeled. We have no information on whether or not layer VI neurons are also rescued, and these would require the appropriate retrograde tracings. With respect to layers II and III, hardly any mutant neurons were seen in these layers of the supercortex (Table 1; Fig. 3B). Mutant cells present in these layers rarely stain with NeuN, suggesting them to be glia.

The mechanism of rescue is unclear; however, existing literature concerning the p35/Cdk5 pathway suggests there are at least two possible (but not mutually exclusive) scenarios, and both invoke non cell-autonomous mechanisms with re- 
spect to p35. First, it has been recently demonstrated that the Reelin-signaling pathway and $\mathrm{p} 35 / \mathrm{Cdk} 5$ pathway have a mutual point of convergence in Dab1 protein (Keshvara et al., 2002). Dab1 is responsive to Reelin binding by tyrosine phosphorylation, but Dab1 is also a substrate for Cdk 5 phosphorylation in its serine residue, raising the speculation that, together, these two signaling pathways modulate the function of Dab1 in controlling neuronal position (Keshvara et al., 2002). Cdk5-deficient mice show impaired Reelin signaling, and the malpositioned neurons beneath the subplate show Dab1 dysfunction. This has prompted the hypothesis that the failure of these neurons to reach the Reelin source present in the marginal zone is responsible for compounding the layering defects. Our observations that layer $\mathrm{V} \mathrm{mu-}$ tant neurons are rescued provide some support for this argument, possibly by the supercortex providing a secondary source of Reelin closer to the ectopically displaced $p 35^{-1-}$ neurons resulting in their rescue. That p35 may also modulate Dab1 function is reflected in their remarkable similarities when comparing $p 35^{-/-}$chimeras with Dab1 $1^{-1-}$ chimeras; both types of compound mice have a superficially segregated supercortex made up of mostly wild-type cells.

Second, the provision of a relatively normal subplate by the supercortex may provide the necessary conditions for rescue and proper positioning of mutant layer V neurons. Mice deficient in either p35 or Cdk5 have malpositioned subplates during development; however, earliest-born neurons that have managed to position themselves correctly with respect to the subplate seem to develop normally, including the possession of normal pyramidal morphologies and properly oriented dendrites (Gilmore et al., 1998; Kwon and Tsai, 1998). If the role of Cdk5 is to partition and compartmentalize the space destined for the cortical plate (Ko et al., 2001), loss of its activator p35 may then be expected to result in laminar disorganization. In this environment, a correctly partitioned cortical plate in the supercortex, together with a properly formed subplate, may lead to partial rescue by attracting some of the incoming mutant layer $\mathrm{V}$ neurons to settle in the supercortex. This interpretation is supported by the finding that the degree of rescue is not related to the number of wild-type layer $\mathrm{V}$ neurons present (Table 2). Other mechanisms may also come into play; for example, the proper orientation of their apical dendrites may represent non cell-autonomous responses to chemoattractants (e.g., semaphorins) that emanate from wild-type layer II/III neurons positioned correctly in the supercortex (Polleux et al., 2000). The lack of rescue among mutant layer II/III neurons is worthy of additional comment. Superficially, this may be attributed to a structural blockade formed by arrested mutant neurons trapped beneath the subplate. However, this does not explain how most wild-type neurons, including those destined for layers II and III, are able to leapfrog over them to reach the supercortex. We conclude there must be something unique to the top layer neurons that require proper intrinsic signaling by $\mathrm{p} 35$. Interestingly, this differential rescue has also been reported when p25, the catalytic product of $\mathrm{p} 35$, is genetically engineered into $p 35^{-1-}$ mice. In these compound mice, p25 is able to partially compensate for $\mathrm{p} 35$, producing full rescue of layer $\mathrm{V}$ neurons, but neurons of layers II and III show only partial rescue (Patzke et al., 2003). Together, these experiments support the hypothesis that earlyborn versus late-born cortical neurons may have different responses to p35/Cdk5 signaling (Gilmore et al., 1998; Gilmore and Herrup, 2001).

\section{Neuronal composition and phenotypes}

As mentioned previously, the analysis of $p 35^{-1-}$ chimeras is informative regarding the function of p35 during cortical development; however, in addition, it also acts as a partial proxy for Cdk5 function. In this light, it is not surprising that $p 35^{-1-}$ chimeras recapitulate some of the cortical phenotypes reported in $C d k 5^{-/-}$ chimeras (Gilmore and Herrup, 2001). First, the cortical space occupied by wild-type cells is reduced in $p 35^{-1-}$ chimeras, and mutant cortical thickness takes up at least half of the entire cortical depth. In comparison, wild-type neurons take up most of the cortical space in $C d k 5^{-1-}$ chimeras and mutant neurons occupy only a narrow strip below wild-type cortical layer V. The expanded mutant cortical space in $p 35^{-1-}$ chimeras may be attributable to compensatory effects of p39 in these neurons (Ko et al., 2001). In this regard, p39 is unlikely to be responsible for the layer $\mathrm{V}$ neuron rescue, because this rescue was not reported in $p 35^{-1-}$ mutant mice where p39 function is still intact. Second, the wildtype zones are infiltrated by mutant neurons but more so in our $p 35^{-1-}$ chimeras. In both instances, the wild-type neurons form a correctly layered supernumerary cortex. Such parallels also extend to the identity of cells in the wild-type cortex, which was overwhelmingly pyramidal in character as evidenced by double staining for Emx1. In contrast, GABAergic neurons (mutant and wild-type) are able to disperse freely throughout the cortical depth without any overt partitioning displayed by their pyramidal counterparts. These observations provide additional support for the contention that the two major populations of cortical neurons, each with its own unique origin and route of migration, have different responses to p35/Cdk5 signaling (Gilmore and Herrup, 2001). This is not unexpected, given that GABAergic interneurons follow tangential routes of migration that do not appear to sychronize with the subplate-cortical plate interface. Instead, interneurons migrate either above or below this interface in the marginal, subventricular, or intermediate zones (Lavdas et al., 1999; Anderson et al., 2001; Wichterle et al., 2001), and hence are likely to be subject to other molecular mechanisms of neuronal positioning.

In summary, these results point to additional facets of p35mediated signaling during the control of cortical neuron migration and positioning. The function of this molecule is clearly not homogeneous to the entire cortical population, with pyramidal and nonpyramidal neurons showing differential responses. Among pyramidal neurons, p35 functions in a predominantly cell-autonomous manner, but non cell-autonomous behavior could also be discerned with differential responses exhibited by early- versus late-born neurons. Such heterogeneity between top and bottom layer neurons has previously been alluded to in connection with the p35 substrate, Cdk5 (Gilmore and Herrup, 2001), and provides a molecular perspective to the emerging view that top and bottom pyramidal neurons may arise from separate precursors (Tarabykin et al., 2001).

\section{References}

Anderson SA, Marin O, Horn C, Jennings K, Rubenstein JL (2001) Distinct cortical migrations from the medial and lateral ganglionic eminences. Development 128:353-363.

Chae T, Kwon YT, Bronson R, Dikkes P, Li E, Tsai LH (1997) Mice lacking p35, a neuronal specific activator of Cdk5, display cortical lamination defects, seizures, and adult lethality. Neuron 18:29-42.

Chan CH, Godinho LN, Thomaidou D, Tan SS, Gulisano M, Parnavelas JG (2001) Emxl is a marker for pyramidal neurons of the cerebral cortex. Cereb Cortex 11:1191-1198.

D’Arcangelo G, Miao GG, Chen SC, Soares HD, Morgan JI, Curran T (1995) A protein related to extracellular matrix proteins deleted in the mouse mutant reeler. Nature 374:719-723. 
Delalle I, Bhide PG, Caviness Jr VS, Tsai LH (1997) Temporal and spatial patterns of expression of $\mathrm{p} 35$, a regulatory subunit of cyclin-dependent kinase 5, in the nervous system of the mouse. J Neurocytol 26:283-296.

Demeulemeester H, Vandesande F, Orban GA, Heizmann CW, Pochet R (1989) Calbindin D-28K and parvalbumin immunoreactivity is confined to two separate neuronal subpopulations in the cat visual cortex, whereas partial coexistence is shown in the dorsal lateral geniculate nucleus. Neurosci Lett 99:6-11.

Dhavan R, Tsai LH (2001) A decade of CDK5. Nat Rev Mol Cell Biol 2:749-759.

Feldman ML (1984) Morphology of the neocortical pyramidal neuron. In: Cerebral cortex (Jones EG, Peters A, eds), pp 123-200. New York: Plenum.

Gao C, Negash S, Guo HT, Ledee D, Wang HS, Zelenka P (2002) CDK5 regulates cell adhesion and migration in corneal epithelial cells. Mol Cancer Res 1:12-24.

Gilmore EC, Herrup K (2001) Neocortical cell migration: GABAergic neurons and cells in layers I and VI move in a cyclin-dependent kinase 5-independent manner. J Neurosci 21:9690-9700.

Gilmore EC, Ohshima T, Goffinet AM, Kulkarni AB, Herrup K (1998) Cyclin-dependent kinase 5-deficient mice demonstrate novel developmental arrest in cerebral cortex. J Neurosci 18:6370-6377.

Gonchar Y, Burkhalter A (1997) Three distinct families of GABergic neurons in rat visual cortex. Cereb Cortex 7:347-358.

Gupta A, Tsai LH, Wynshaw-Boris A (2002) Life is a journey: a genetic look at neocortical development. Nat Rev Genet 3:342-355.

Hammond V, Howell B, Godinho L, Tan SS (2001) disabled-1 functions cell autonomously during radial migration and cortical layering of pyramidal neurons. J Neurosci 21:8798-8808.

Hevner RF, Shi L, Justice N, Hsueh Y, Sheng M, Smiga S, Bulfone A, Goffinet AM, Campagnoni AT, Rubenstein JL (2001) Tbr1 regulates differentiation of the preplate and layer 6. Neuron 29:353-366.

Homayouni R, Curran T (2000) Cortical development: Cdk5 gets into sticky situations. Curr Biol 10:R331-R334.

Howell BW, Hawkes R, Soriano P, Cooper JA (1997) Neuronal position in the developing brain is regulated by mouse disabled-1. Nature 389:733-737.

Ino H, Ishizuka T, Chiba T, Tatibana M (1994) Expression of CDK5 (PSSALRE kinase), a neural cdc2-related protein kinase, in the mature and developing mouse central and peripheral nervous systems. Brain Res 661:196-206.

Keshvara L, Magdaleno S, Benhayon D, Curran T (2002) Cyclin-dependent kinase 5 phosphorylates disabled 1 independently of Reelin signaling. J Neurosci 22:4869-4877.

Ko J, Humbert S, Bronson RT, Takahashi S, Kulkarni AB, Li E, Tsai LH (2001) p35 and p39 are essential for cyclin-dependent kinase 5 function during neurodevelopment. J Neurosci 21:6758-6771.

Kwon YT, Tsai LH (1998) A novel disruption of cortical development in p35(-/-) mice distinct from reeler. J Comp Neurol 395:510-522.

Kwon YT, Tsai LH, Crandall JE (1999) Callosal axon guidance defects in p35(-/-) mice. J Comp Neurol 415:218-229.

Kwon YT, Gupta A, Zhou Y, Nikolic M, Tsai LH (2000) Regulation of $\mathrm{N}$-cadherin-mediated adhesion by the p35-Cdk5 kinase. Curr Biol 10:363-372.

Lavdas AA, Grigoriou M, Pachnis V, Parnavelas JG (1999) The medial ganglionic eminence gives rise to a population of early neurons in the developing cerebral cortex. J Neurosci 19:7881-7888.

Mintz B (1970) Gene expression in allophenic mice. In: Control mechanisms in the expression of cellular phenotypes (Padykula HA, ed), pp 15-42. New York: Academic.

Negash S, Wang HS, Gao C, Ledee D, Zelenka P (2002) Cdk5 regulates cell-matrix and cell-cell adhesion in lens epithelial cells. J Cell Sci 115:2109-2117.

Niethammer M, Smith DS, Ayala R, Peng J, Ko J, Lee MS, Morabito M, Tsai LH (2000) NUDEL is a novel Cdk5 substrate that associates with LIS1 and cytoplasmic dynein. Neuron 28:697-711.

Nikolic M, Dudek H, Kwon YT, Ramos YF, Tsai LH (1996) The cdk5/p35 kinase is essential for neurite outgrowth during neuronal differentiation. Genes Dev 10:816-825.

Ohshima T, Ward JM, Huh CG, Longenecker G, Veeranna, Pant HC, Brady
RO, Martin LJ, Kulkarni AB (1996) Targeted disruption of the cyclindependent kinase 5 gene results in abnormal corticogenesis, neuronal pathology and perinatal death. Proc Natl Acad Sci USA 93:11173-11178.

Ohshima T, Gilmore EC, Longenecker G, Jacobowitz DM, Brady RO, Herrup K, Kulkarni AB (1999) Migration defects of cdk5(-/-) neurons in the developing cerebellum is cell autonomous. J Neurosci 19:6017-6026.

Ohshima T, Ogawa M, Veeranna, Hirasawa M, Longenecker G, Ishiguro K, Pant HC, Brady RO, Kulkarni AB, Mikoshiba K (2001) Synergistic contributions of cyclin-dependant kinase 5/p35 and Reelin/Dab1 to the positioning of cortical neurons in the developing mouse brain. Proc Natl Acad Sci USA 98:2764-2769.

Patzke H, Maddineni U, Ayala R, Morabito M, Volker J, Dikkes P, Ahlijanian MK, Tsai LH (2003) Partial rescue of the p35-/- brain phenotype by low expression of a neuronal-specific enolase p25 transgene. J Neurosci 23:2769-2778.

Polleux F, Morrow T, Ghosh A (2000) Semaphorin 3A is a chemoattractant for cortical apical dendrites. Nature 404:567-573.

Rice DS, Curran T (2001) Role of the reelin signaling pathway in central nervous system development. Annu Rev Neurosci 24:1005-1039.

Sasaki S, Shionoya A, Ishida M, Gambello MJ, Yingling J, Wynshaw-Boris A, Hirotsune S (2000) A LIS1/NUDEL/cytoplasmic dynein heavy chain complex in the developing and adult nervous system. Neuron 28:681-696.

Sheldon M, Rice DS, D’Arcangelo G, Yoneshima H, Nakajima K, Mikoshiba K, Howell BW, Cooper JA, Goldowitz D, Curran T (1997) Scrambler and yotari disrupt the disabled gene and produce a reeler-like phenotype in mice. Nature 389:730-733.

Shetty KT, Link WT, Pant HC (1993) cdc2-like kinase from rat spinal cord specifically phosphorylates KSPXK motifs in neurofilament proteins: isolation and characterization. Proc Natl Acad Sci USA 90:6844-6848.

Sturm KS, Berger CN, Zhou SX, Dunwoodie SL, Tan S-S, Tam PPL (1997) Unrestricted lineage differentiation of parthenogenetic ES-cells. Dev Genes Evol 206:377-388.

Tan S-S, Williams EA, Tam PPL (1993) X-chromosome inactivation occurs at different times in different tissues of the post-implantation mouse embryo. Nat Genet 3:170-174.

Tan S-S, Kalloniatis M, Sturm K, Tam PPL, Reese BE, Faulkner-Jones BE (1998) Separate progenitors for radial and tangential cell dispersion during development of the cerebral neocortex. Neuron 21:295-304.

Tarabykin V, Stoykova A, Usman N, Gruss P (2001) Cortical upper layer neurons derive from the subventricular zone as indicated by Svetl gene expression. Development 128:1983-1993.

Tomizawa K, Matsui H, Matsushita M, Lew J, Tokuda M, Itano T, Konishi R, Wang JH, Hatase O (1996) Localization and developmental changes in the neuron-specific cyclin-dependent kinase 5 activator (p35nck5a) in the rat brain. Neuroscience 74:519-529.

Trommsdorff M, Gotthardt M, Hiesberger T, Shelton J, Stockinger W, Nimpf J, Hammer RE, Richardson JA, Herz J (1999) Reeler/Disabled-like disruption of neuronal migration in knockout mice lacking the VLDL receptor and ApoE receptor 2. Cell 97:689-701.

Tsai LH, Takahashi T, Caviness Jr VS, Harlow E (1993) Activity and expression pattern of cyclin-dependent kinase 5 in the embryonic mouse nervous system. Development 119:1029-1040.

Tsai LH, Delalle I, Caviness Jr VS, Chae T, Harlow E (1994) p35 is a neuralspecific regulatory subunit of cyclin-dependent kinase 5. Nature 371:419-423.

van Brederode JF, Helliesen MK, Hendrickson AE (1991) Distribution of the calcium-binding proteins parvalbumin and calbindin-D28k in the sensorimotor cortex of the rat. Neuroscience 44:157-171.

Vogel US, Reynolds R, Thompson RJ, Wilkin GP (1988) Expression of the $2^{\prime}, 3^{\prime}$-cyclic nucleotide $3^{\prime}$-phosphohydrolase gene and immunoreactive protein in oligodendrocytes as revealed by in situ hybridization and immunofluorescence. Glia 1:184-190.

Wichterle H, Turnbull DH, Nery S, Fishell G, Alvarez-Buylla A (2001) In utero fate mapping reveals distinct migratory pathways and fates of neurons born in the mammalian basal forebrain. Development 128:3759-3771.

Zheng M, Leung CL, Liem RK (1998) Region-specific expression of cyclindependent kinase 5 (cdk5) and its activators, p35 and p39, in the developing and adult rat central nervous system. J Neurobiol 35:141-159. 